PAPER

An intubation catheter integrated with flow sensors and smart actuators for characterizing airflow patterns in stenosed trachea: an objective guide for CAO management

To cite this article: B Alekya et al 2021 J. Micromech. Microeng. 31055007

View the article online for updates and enhancements.

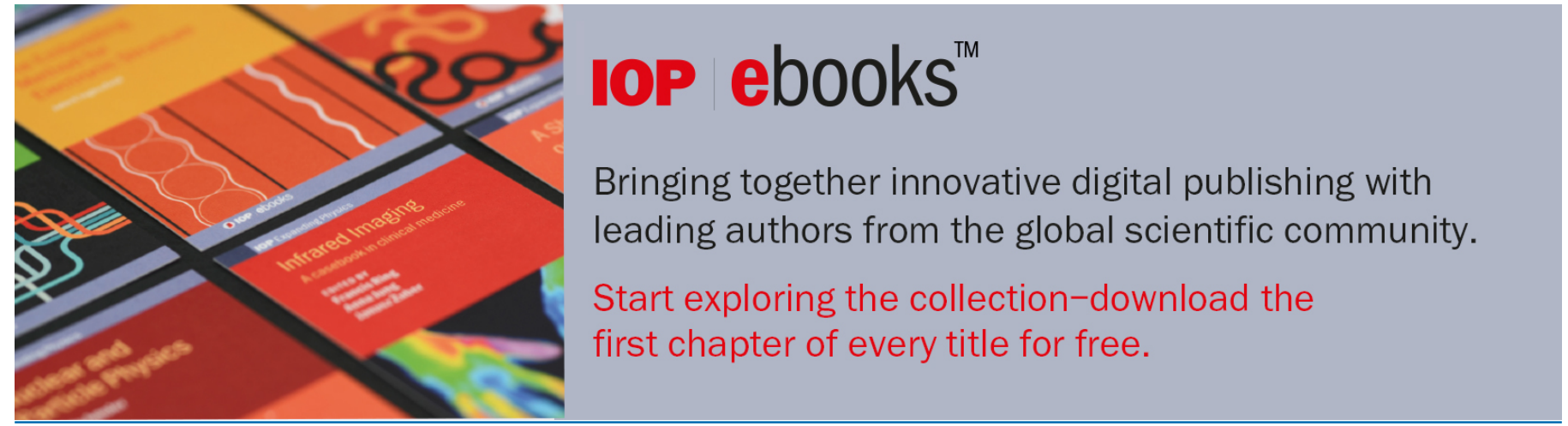

This content was downloaded from IP address 14.139 .128 .34 on $23 / 07 / 2021$ at $10: 15$ 


\title{
An intubation catheter integrated with flow sensors and smart actuators for characterizing airflow patterns in stenosed trachea: an objective guide for CAO management
}

\author{
B Alekya ${ }^{1}$, V S N Sitaramgupta $\mathbf{V}^{1}$, B S Arjun ${ }^{1}$, V Bhushan $^{1}{ }^{\mathbb{D}}$, Kevin Abishek ${ }^{1}{ }^{\mathbb{D}}$, \\ Sanjay $\mathbf{R a O}^{2}$ (i), Yeongjin Kim ${ }^{3,4, *}$ and Hardik J Pandya ${ }^{1, *}$ (C) \\ ${ }^{1}$ Department of Electronic Systems Engineering, Division of EECS, Indian Institute of Science, \\ Bangalore, India \\ ${ }^{2}$ Department of Pediatric Surgery, Mazumdar Shaw Multispecialty Hospital, Narayana Health, \\ Bangalore, India \\ ${ }^{3}$ Division of Thermal and Fluids Science, Institute for Computational Science; Faculty of Electrical and \\ Electronics Engineering, Ton Duc Thang University, Ho Chi Minh City, Vietnam \\ ${ }^{4}$ Department of Mechanical Engineering, Incheon National University, 8-204, 119 Academy-ro, \\ Yeonsu-gu, Incheon, Republic of Korea \\ E-mail: hjpandya@iisc.ac.in and ykim@inu.ac.kr
}

Received 8 January 2021, revised 13 March 2021

Accepted for publication 29 March 2021

Published 9 April 2021

\begin{abstract}
Stenosis reduces the effective lumen area in the tracheal and bronchial segments of the airway anatomy. Loss in patency due to obstruction increases resistance to airflow; thus, severe narrowing is often associated with morbidity and mortality. Etiologies such as congenital tracheal stenosis, tracheomalacia, laryngeal and subglottic stenosis, atresia are few among the many pathologies causing major airway obstruction and respiratory distress. Diagnosis of such anomalies is usually based on clinical suspicion due to the non-specificity of the associated clinical symptoms. Visual assessment using conventional bronchoscopy or radiography images from CT scan for precisely locating obstruction site is highly subject to clinician's expertise. Characterizing airflow patterns in stenosed airway calls for newer diagnostic tools that can effectively quantify changes in airflow due to construction sites. Our work presents a steerable intubation catheter that can quantitatively measure air velocity across various segments of the tracheobronchial tree. The catheter consists of a three-layer flexible printed circuit board integrated with micro-electro-mechanical system-based thermal flow sensors and a pair of sub-millimeter helical shape memory actuators. Flow distribution is measured in excised sheep tracheal tissues at 15, 30, 50, 65, and $801 \mathrm{~min}^{-1}$ for normal and stenosed conditions. Even a $10 \%$ reduction in lumen area generated unique peaks corresponding to the obstruction site; thus, the catheter can locate stenosis at the precritical stage. For 50\% tracheal obliteration, the sensor closest to stenosis showed a 2.4-fold increase in velocity when tested for reciprocating flows. Thus, flow rate scales quadratically with reducing cross-section area, contributing to increased airflow resistance.
\end{abstract}


Supplementary material for this article is available online

Keywords: tracheal airflow, intubation catheter, MEMS-based flow sensors, SMA actuators, flexible PCB

(Some figures may appear in colour only in the online journal)

\section{Introduction}

Central airway obstruction (CAO) refers to constriction in the trachea and main-stem bronchi of the respiratory tract. CAO can be acquired (post-intubation and tracheostomy induced stenosis) [1-3] or congenital [4, 5], benign [6, 7] or malignant [8] and can be acute (collapse within minutes) or chronic (progressive damage), with dynamic or fixed obstruction [9], causing respiratory distress in both adult and child population. However, the risk due to constriction remains higher in the pediatric population due to their smaller airway geometry [10].

Management of CAO remains a diagnostic and therapeutic challenge due to the variability in the presentation of clinical symptoms. Severely constricted airways often warrant careful monitoring to determine appropriate management strategy. Diagnostic workup often involves collective decision making by a diversified team of clinicians as the complexity in anomalies demand patient-centric management [11]. Apart from a clear and thorough understanding of the underlying cause of the disorder, timely diagnosis depends on the availability of a multidisciplinary team with experience in use of sophisticated (advanced, cutting-edge) tools such as endoscopy, imaging along with expertise in relevant surgical tools and technology. Diagnosis of CAO involves pulmonary function test [12], radiological scans [13], followed by interventional bronchoscopy [14] and/or surgical intervention [15]. Spirometry, a type of pulmonary function test, generates flow-volume curves that reflect the airway caliber only in case of severe stenosis, and an abnormal flow-volume loop indicates a reduction in inspiratory flow. The test is insensitive to mild and moderate reductions in the airway caliber and inadequate to locate the site of obstruction. Additionally, this test requires patient cooperation and hence is not possible in young children. Radiological scans using multidetector computed tomography combined with $3 \mathrm{D}$ volume rendering and virtual bronchoscopy provides vital information such as location, type, and length of obstruction. However, a retrospective study on radiology reports has recorded instances where radiologists failed to recognize $\mathrm{CAO}$ in patients with no prior clinical records. The study also observed how CT reports could be misleading due to an overestimation of obstruction [16]. Interventional bronchoscopy remains a gold standard technique is assessing airway pathologies; however, the assessment is again subject to the availability of a skilled bronchoscopist. A study by Murgu and Colt unveils how airway strictures assessed using still bronchoscopic images have been misclassified even by experienced bronchoscopist [17]. Although the information on localized airflow patterns is a direct measure of airway caliber, only imaging modalities have seen significant technological evolution. Information on the location/site of obstruction can be discerned quantitatively using airflow patterns generated within the tracheobronchial tree. Alterations in the pattern can be used to delineate healthy and stenosed airways. As of today, there is no tool to measure and objectively describe tracheabronchial obstruction. A technology/method to delineate mild, moderate, and severe airway constrictions can improve CAO management and is an area of active research.

Several computational fluid dynamics (CFD) studies have been performed [18] to understand the impact of tracheal compression on airflow patterns starting from its early stage. Table 1 briefly discusses research objectives, findings and methods used for determining airflow patterns in normal and constricted anatomies.

Airway narrowing in the pediatric population can be extremely debilitating due to the relatively smaller anatomical geometry. Even a small reduction in cross-section area (CSA) can increase the resistance to flow exponentially (from HagenPoiseuille's equation, the resistance to airflow is inversely proportional to forth power of tracheal radius). Average tracheal diameter for infants, children and adults ranges from 8,15 and $20 \mathrm{~mm}$ with tracheal length 50,120 and $150 \mathrm{~mm}$ [26]. Mean axial flow velocities are 2.2, 1.8 and $1.4 \mathrm{~m} \mathrm{~s}^{-1}$ for a healthy tracheobronchial anatomy. From literature male counterparts have higher anatomical geometry compared to females and the airflow velocities decreases with age [27].

The clinical progress of a child suffering from chronic airway disease operated with underwent tracheal transplant has reported [28]. Following tracheal transplant/replacement, multiple stents were introduced periodically to overcome the tracheobronchial stenosis due to the graft's malacic nature. CFD simulations were performed using the CT scan data of the child collected for over 4 years. Although the first year demonstrated a smooth and normal airflow profile in the transplant, a rising peak in the trachea's distal end with an increase in velocity was observed in the third year and a further two-fold increase in the fourth year. The high-velocity region was identified to be the stenosed segment corrected by multiple stent insertion. The study was limited by the need for an intraoperative tool that can measure airflow profile across various segments of the tracheobronchial tree for efficient tracheal replacements. CFD's limitation can be overcome using a test bench set-up, which represents close to anatomic reality.

In this work, we develop an intubation catheter integrated with flow sensors and antagonistic shape memory actuators to manage CAO (figure 1). The flow sensor array yields airflow patterns across various segments of the tracheobronchial tree. Our study shows that the airflow rate close to the stenosis section is higher than the healthy section due to the constriction of airflow. This increased airflow rate can be measured by 
Table 1. Techniques adopted for $\mathrm{CAO}$ and respiratory flow pattern generation.

\begin{tabular}{|c|c|c|c|}
\hline Reference & Objective & Method used & Research findings \\
\hline Brouns et al [19] & $\begin{array}{l}\text { Airflow dynamics in stenosed } \\
\text { airways were studied at } 15 \\
\text { and } 301 \mathrm{~min}^{-1} \text { flow rates for } \\
50 \%, 75 \%, 80 \%, 85 \% \text {, and } \\
90 \% \text { stenotic constriction }\end{array}$ & $\begin{array}{l}\text { Realistic CFD models were } \\
\text { developed using CT scan data } \\
\text { for } 2 \text { and } 30 \mathrm{~mm} \text { tracheal } \\
\text { stenotic length }\end{array}$ & $\begin{array}{l}\text { For constrictions upto } 75 \% \text {, } \\
\text { relatively moderate change } \\
\text { in pressure drop ( } 7 \mathrm{~Pa} \text { ) was } \\
\text { observed for both the flow rates } \\
\text { Severe constrictions }(84 \% \text { and } 91 \%) \\
\text { have a steep rise in pressure drop } \\
(46 \mathrm{~Pa} \text { and } 235 \mathrm{~Pa} \text { ) }\end{array}$ \\
\hline Bates et al [20] & $\begin{array}{l}\text { Investigate power losses in } \\
\text { goiter-induced tracheal } \\
\text { pathologies }\end{array}$ & $\begin{array}{l}\text { CFD studies were performed to } \\
\text { understand the contribution of } \\
\text { tracheal curvature and } \\
\text { constriction on work of } \\
\text { breathing and breathing } \\
\text { efficiency to determine resistive } \\
\text { losses }\end{array}$ & $\begin{array}{l}\text { Increased wall shear stress (WSS) in } \\
\text { constricted geometries contributed } \\
\text { to a rise in frictional losses. } \\
\text { Curvature in tracheal geometry } \\
\text { increases unsteadiness in flow, } \\
\text { contributing to interior flow losses. }\end{array}$ \\
\hline Zhu et al [21] & $\begin{array}{l}\text { Identifying the right surgical } \\
\text { corrective order in complex } \\
\text { congenital tracheal stenosis is } \\
\text { vital to minimize the risk of } \\
\text { tracheal collapse in new-borns }\end{array}$ & $\begin{array}{l}\text { CFD and computer-generated } \\
\text { model of an infant having } \\
\text { multisegmental stenosis was } \\
\text { used to evaluate the success rate } \\
\text { of surgical correction }\end{array}$ & $\begin{array}{l}\text { Quantifying internal pressure } \\
\text { and velocity fluctuations can } \\
\text { aid corrective order resection. } \\
\text { Exhaustive iteration of the } 3 \mathrm{D} \text { model } \\
\text { at several instants of staged correction } \\
\text { makes the whole process challenging }\end{array}$ \\
\hline Chen et al [22] & $\begin{array}{l}\text { Alterations in flow velocity } \\
\text { and pressure in } 12 \text { patients } \\
\text { suffering from vascular } \\
\text { ring-induced tracheal stenosis }\end{array}$ & $\begin{array}{l}\text { Parameters such as velocity, } \\
\text { pressure drop were analyzed } \\
\text { using CFD-based reconstructed } \\
\text { trachea images. }\end{array}$ & $\begin{array}{l}\text { At } 0.01,0.1 \text { and } 1 \mathrm{~m} \mathrm{~s}^{-1} \text { inlet velocity } \\
\text { the compressed regions showed higher } \\
\text { velocity peaks for all flow rates. } \\
\text { The expiratory phase showed higher } \\
\text { turbulence intensity than the inspirat- } \\
\text { ory cycle. }\end{array}$ \\
\hline Hollister et al [23] & $\begin{array}{l}\text { Model pediatric } \\
\text { tracheomalacia, a clinical } \\
\text { condition that causes sudden } \\
\text { airway collapse }\end{array}$ & $\begin{array}{l}\text { CFD was used to understand } \\
\text { correlation between percentage } \\
\text { reduction in tissue mechanical } \\
\text { property, exhalation pressures, } \\
\text { tracheal diameter, malacic } \\
\text { segment length, and several } \\
\text { other factors responsible for } \\
\text { instability and tracheal collapse. }\end{array}$ & $\begin{array}{l}\text { A } 1 \mathrm{~cm} \text { malacic tissue leads } \\
\text { to sudden airway collapse. } \\
\text { The limitation with the computational } \\
\text { model is that postulated tissue } \\
\text { properties mimic the real vis- } \\
\text { coelastic properties only to an extent. } \\
\text { Clinical translation demands } \\
\text { experiments using animal models. }\end{array}$ \\
\hline Noma et al [24] & $\begin{array}{l}\text { Measure airflow to determine } \\
\text { breathing and heartbeat in } \\
\text { laboratory animals }\end{array}$ & $\begin{array}{l}\text { MEMS-based thermal flow } \\
\text { sensor }\end{array}$ & $\begin{array}{l}\text { Fourier Transform on the data } \\
\text { obtained from the implanted stent } \\
\text { flow sensor could generate breathing } \\
\text { and heartbeat signals }\end{array}$ \\
\hline $\begin{array}{l}\text { Kawamoto et al } \\
\text { [25] }\end{array}$ & $\begin{array}{l}\text { Flow and pressure } \\
\text { measurement to analyze local } \\
\text { airway resistance in the lungs }\end{array}$ & $\begin{array}{l}\text { MEMS-based micro-machined } \\
\text { pressure and thermal-flow } \\
\text { sensors }\end{array}$ & $\begin{array}{l}\text { For a } 0.5 \mathrm{~Hz} \text { reciprocating flow, pres- } \\
\text { sure changes in the lung due to resist- } \\
\text { ance could be detected using the probe } \\
\text { system. }\end{array}$ \\
\hline
\end{tabular}

the sensors and the flow patterns directly corresponds to the degree of constriction.

\section{Materials and methods}

\subsection{Sensor fabrication and characterization}

The process flow for fabrication of micro-electro-mechanical system (MEMS)-based thermal flow sensors is shown in figure 2(A). Wafer pre-processing: The mask layout was designed using $\mathrm{CleW}$ in 5.0 and then transferred on a 5 inch soda-lime glass using Heidelberg $\mu$ PG 501 mask writer. The mask was developed using $\mathrm{AZ} \mathrm{Z}^{\circledR} 351 \mathrm{~B}$ developer and DI water taken in 1:4 ratio with development time close to $60 \mathrm{~s}$. As a wafer pre-processing step, $500 \mu \mathrm{m}, 4$ inch, single side polished, (100), n-type silicon wafer was rinsed in acetone then IPA solution for $2 \mathrm{~min}$ each, followed by dehydration bake at $110{ }^{\circ} \mathrm{C}$ for $5 \mathrm{~min}$.

(a) The silicon wafer was then thermally oxidized at $1150{ }^{\circ} \mathrm{C}$ in a pyrogenic furnace to grow $1 \mu \mathrm{m}$ silicon dioxide $\left(\mathrm{SiO}_{2}\right)$, (b) the oxidized wafer was spin-coated using hexamethyldisilazane at $6000 \mathrm{rpm}, 40 \mathrm{~s}$; baked at $110{ }^{\circ} \mathrm{C}$ for $1 \mathrm{~min}$ followed by $5 \mathrm{~min}$ relaxation. The wafer was then spin-coated with S1813, positive resist at $4000 \mathrm{rpm}, 40 \mathrm{~s}$; soft-baked $110{ }^{\circ} \mathrm{C}$ for 1 min, (c) Suss MJB4 Mask Aligner was used for photomask alignment and UV exposure with $8 \mathrm{~s}$ exposure time, (d) the exposed wafer is then developed using MF26 A developer for $30 \mathrm{~s}$ and hard baked at $110^{\circ} \mathrm{C}$ 
CENTRAL AIRWAY OBSTRUCTION MANAGEMENT TOOL

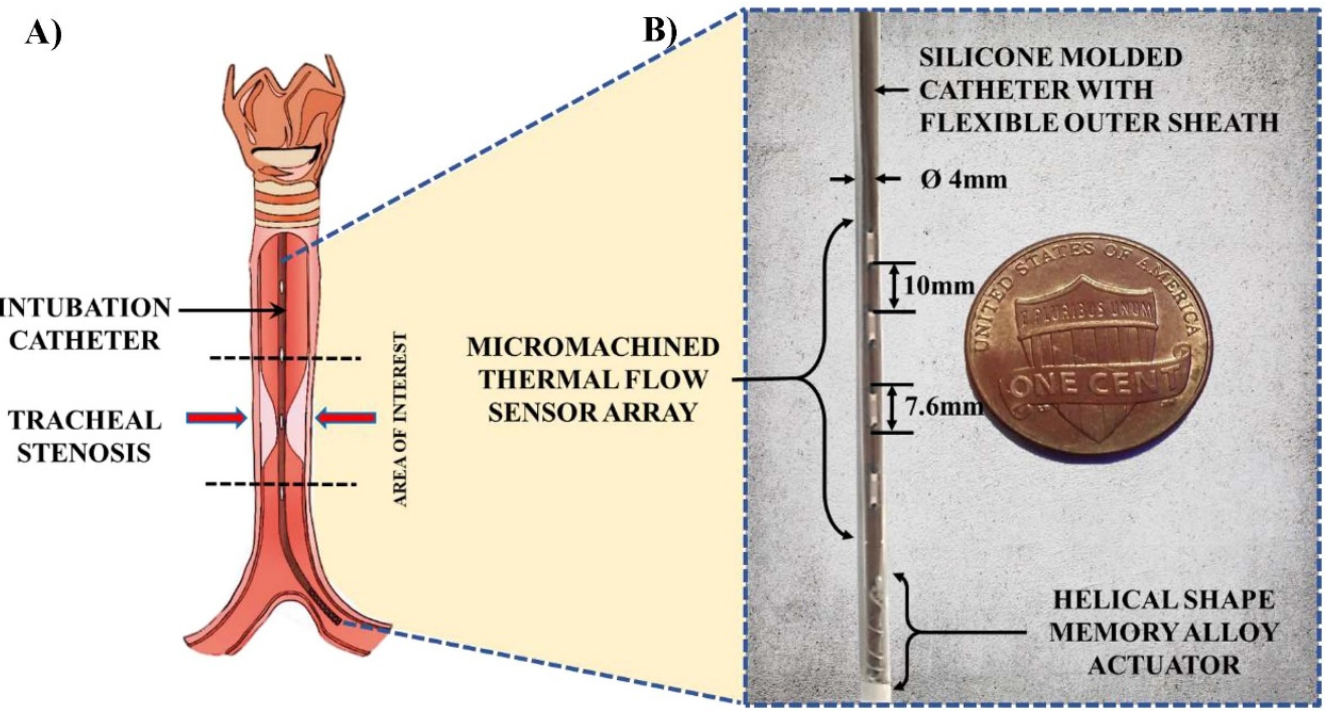

Figure 1. (A) Schematic representation of intubation catheter advanced through tracheal stenosis, (B) optical image of the fabricated catheter showing integrated sensors and SMA actuator.
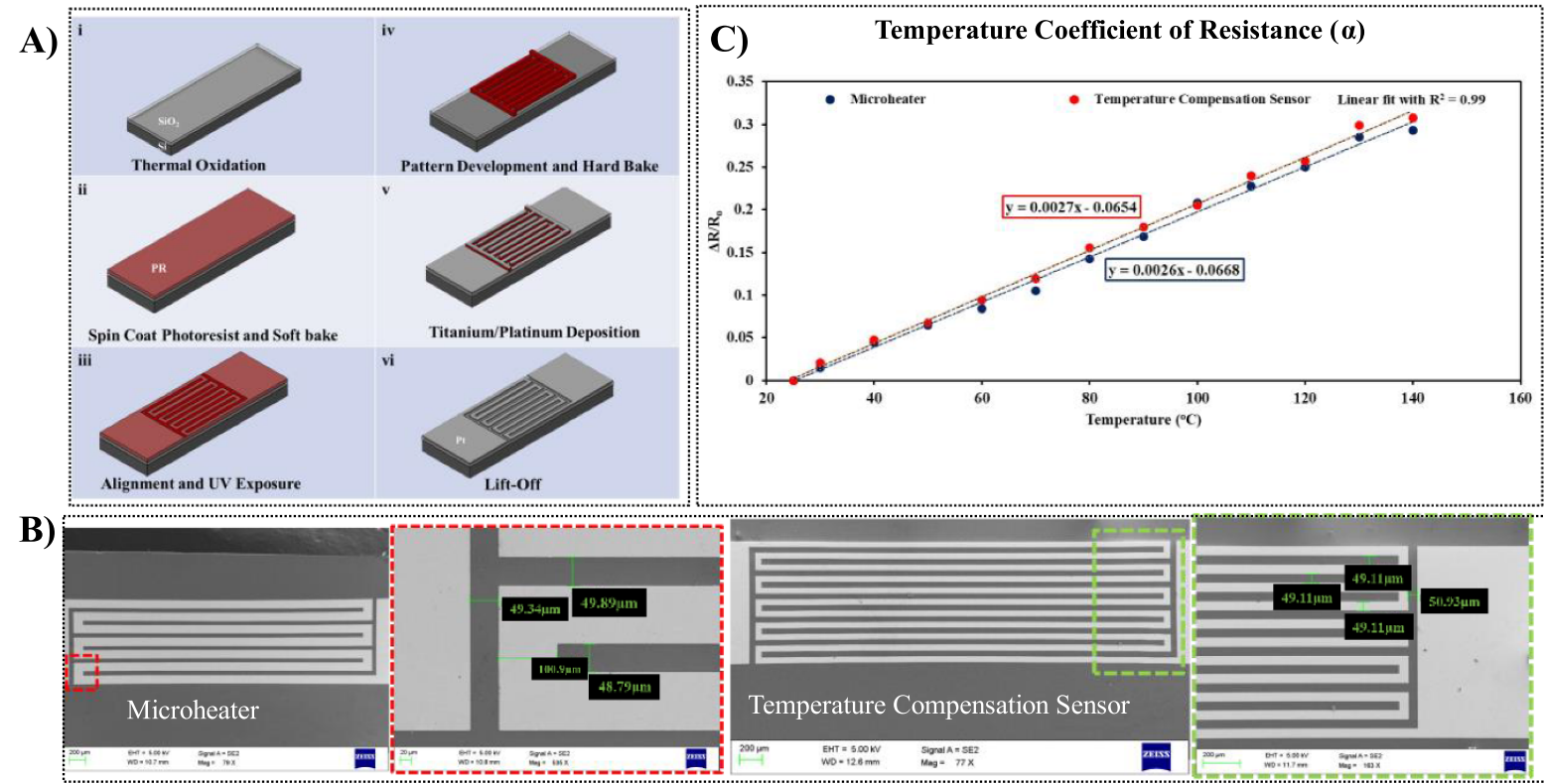

Figure 2. (A) Process flow for fabrication of microthermal flow sensor array, (B) TCR curve for the fabricated platinum sensors, and (C) SEM images of the microheater and temperature compensation sensor.

for $3 \mathrm{~min}$, (e) a $35 \mathrm{~nm}$ titanium (Ti) followed by $195 \mathrm{~nm}$ platinum $(\mathrm{Pt})$ was sputter-coated on the wafer patterned with photoresist, (f) the lift-off process was performed to pattern the platinum microheaters. The wafer was then diced using automatic dicer (DAD321), with each die measuring $7.5 \mathrm{~mm} \times 1 \mathrm{~mm}$. The scanning electron microscopy (SEM) images of the fabricated heater and temperature compensation sensor are shown in figure 2(B). At room temperature, the resistance of the microheater is $152 \Omega$, and that of temperature sensor is $1257.3 \Omega$. The change in resistance for every $10^{\circ} \mathrm{C}$ rise in temperature was recorded to determine the temperature coefficient of resistance (TCR) (figure 2(C)). The TCR was found to be linear with values $0.0026{ }^{\circ} \mathrm{C}^{-1}$ for microheater and $0.0027{ }^{\circ} \mathrm{C}^{-1}$ for the temperature compensation sensor.

\subsection{FPCB design and senor integration}

The catheter diameter ( $4 \mathrm{~mm}$ ) was calculated considering the worst-case scenario of stenosed tracheal diameters. Thus, the flexible printed circuit board (FPCB) width was fixed to $3 \mathrm{~mm}$. For this prototype, a simple arrangement accommodating four microheaters, temperature sensors, and a pair of SMA actuators are required. The layout of the FPCB is such that sensors and actuators are on the distal end and the interconnect probe pads for accessing these components are on the proximal end. 


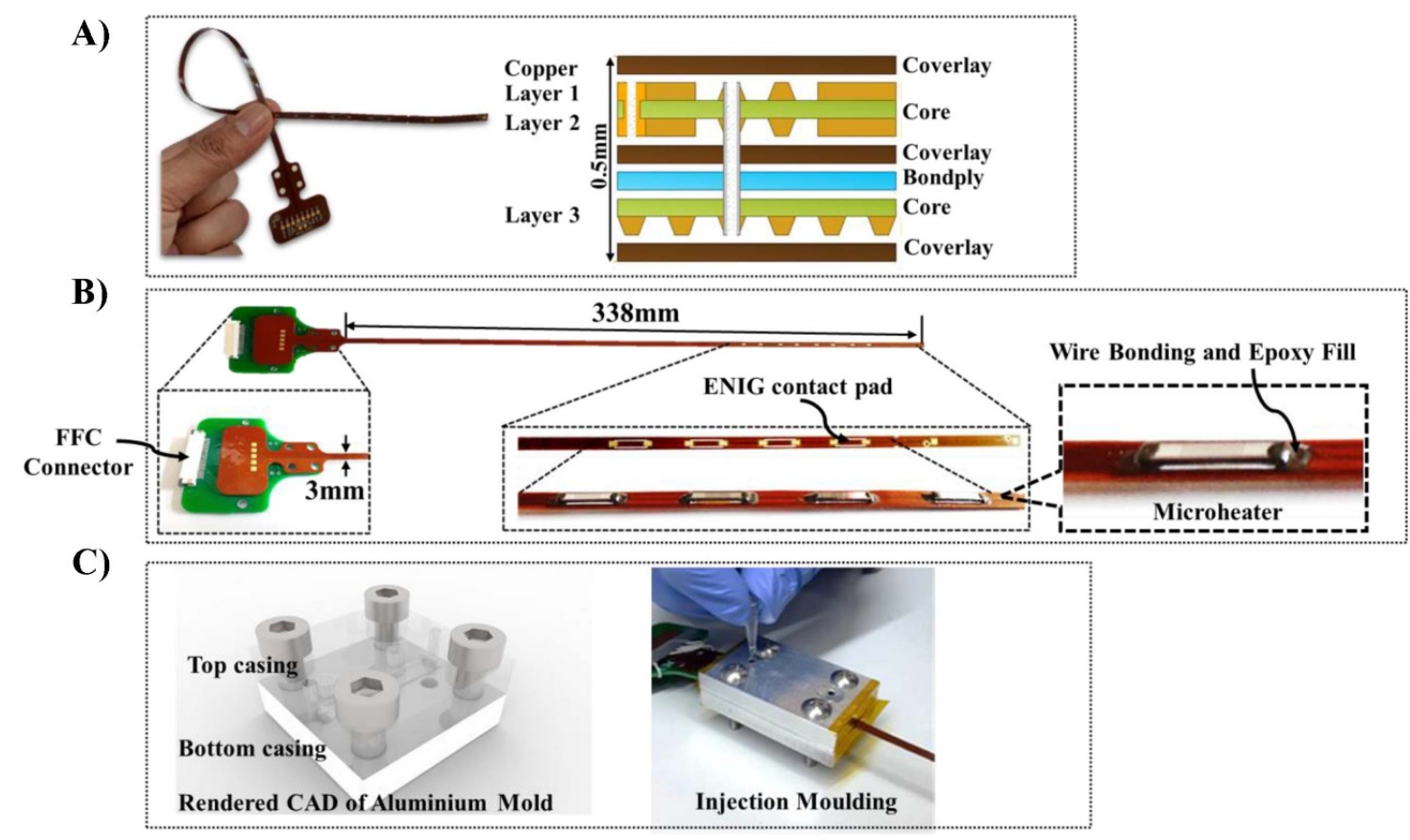

Figure 3. (A) Flexible PCB and corresponding PCB stack up, (B) integration of the fabricated sensor with the PCB, and (C) custom-built mold for silicone injection molding of the catheter.

The long length of the catheter with sensors and SMA actuators positioned on the distal end facilitate control over navigation as it is advanced through the complex airway anatomy. The horseshoe-shaped cartilage rings each $2 \mathrm{~mm}$ wide is interconnected with $1 \mathrm{~mm}$ wide connective tissue. The sensor die size can be suitably adjusted such that the localized flow patterns relate with the health condition of the closest cartilageconnective tissue pairs. The catheter is gradually advanced from the proximal trachea to the median followed by the distal end towards the carina. At each stage, the sensor data can be monitored and further advanced downward to ensure minimal intervention. Positioning the sensor array at the distal end gives scope for immediate exposure of the sensing region to the targeted site with minimal artifact as the presence of catheter in the channel can further increase resistance to flow.

The FPCB stack up can be further increased from three layers to four or even six, leveraging this feature the catheter can be accommodated with additional sensors without increasing the overall diameter. The actuator at the proximal end allows steering the tip through angulations and constrictions in the channel.

Although the FPCB is pliant, mounting the silicon die reduces the bending capability. Alternately, the FPCB can be integrated with sensors that are conformal or developed on flexible substrates. The long interconnect lines connecting the sensors to the distal end of the catheter adds to the wiring resistance, however, this can be minimized using a four-wire measurement with current drive-in which nullifies the effect of interconnect resistance.

With the FPCB width fixed, the total number of interconnect lines required were 17 . From manufacturing capabilities, the minimum trace gap and track width is 3 mil, hence, the distribution of the lines on a single side is not feasible. Also, it would not be practical to have thin traces suit the SMA's high current requirements. Thus, the lines are split into three layers, as shown in figure 3(A). The top layer consists of 11 mil width lines for microheater, the middle layer containing 20 mil width for SMA, and the bottom layer containing 7.8 mil width for the temperature sensor. EAGLE CAD software was used to design the FPCB. At the proximal end, the FPCB is held to a rigid PCB with aligning holes and electrical connections by solder (figure 3(B)). Both PCBs were sandwiched between a $3 \mathrm{D}$ printed casing with the use of $\mathrm{M} 3$ bolts. The connections from the rigid PCB were brought to a separate PCB for easy access for designing the signal conditioning circuit. Each sensor die was wire bonded to electroless nickel immersion gold finished pads on the FPCB and then capsulated using epoxy fill. In general, catheters are produced by injection molding, which uses medical-grade liquid silicone injected into a sealed mold inside a cleanroom environment. However, the apparatus and standard molding process are expensive due to the material cost, mold type, and sophisticated machining tools. We designed an alternative technique to fabricate the catheter using aluminum mold that was CNC machined, and Polydimethylsiloxane (PDMS) polymer was infused into the mold holding the FPCB and sensors. The assembly containing the mold, FPCB, sensors, and PDMS plus curing agent mixture was then cured overnight at $70^{\circ} \mathrm{C}$. As a prototype and proof of concept, the fabricated catheter did suffice for our laboratory experiments, although it does not comply with all the medical manufacturing guidelines (figure 3(C)). 

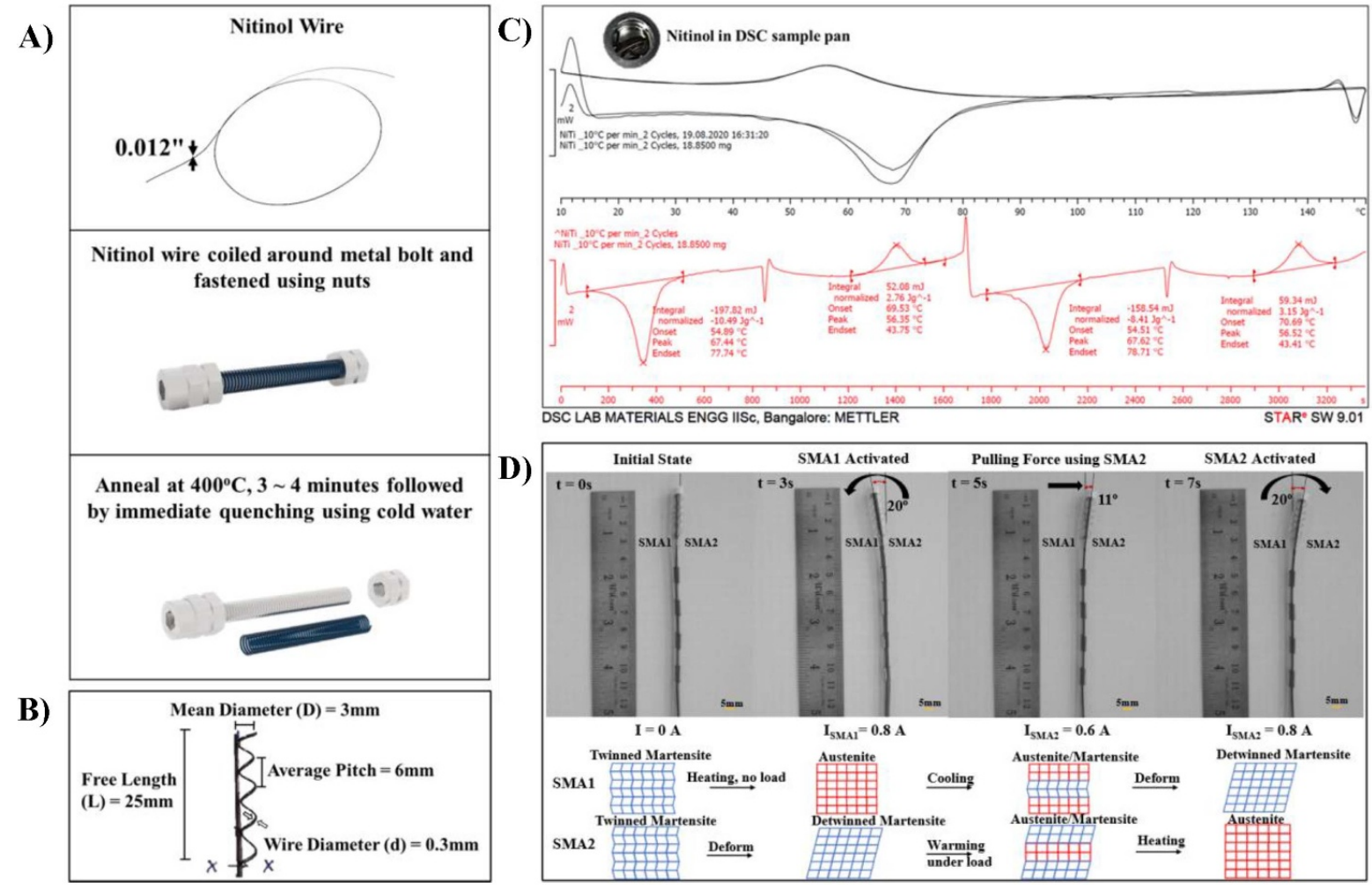

Figure 4. (A) Training steps to fabricate helical spring SMA, (B) the parameters of the final spring coil bonded on the FPCB, (C) DSC characterization of Nitinol sample, and (D) antagonistic SMA assembly on the FPCB with flow sensors.

\subsection{SMA training and characterization}

As the intubation catheter is designed for measurement in the trachea and main stem bronchi, the catheter is integrated with SMA actuators at the distal end to generate bending forces. The helical spring actuator's low mass and high stroke make it an optimum choice for catheter integration. To make the helical spring actuator, $0.012^{\prime \prime}$ nitinol wire was procured from Dynalloy, Inc. The wire was coiled around bolt of desired pitch and restrained using a nut at both ends (figure 4(A)). The assembly was then subjected to thermal annealing using a flame torch at $400{ }^{\circ} \mathrm{C}$ for $\sim 3 \mathrm{~min}$ and then dropped into cold water. The trained SMA spring index, coil diameter, and pitch used for the catheter are shown in figure 4(B). The transformation temperatures such as austenite start and finish $\left(A_{\mathrm{s}}\right.$, $\left.A_{\mathrm{f}}\right)$ and martensite start and finish $\left(M_{\mathrm{s}}, M_{\mathrm{f}}\right)$ for $18 \mathrm{mg}$ Nitinol sample was obtained using differential scanning calorimetry test (DSC), that was run for two cycles in steps of $10{ }^{\circ} \mathrm{C}$ (figure 4(C)). The wide range of transformation temperatures gives scope for better control of the actuator bending. The distal end (free length) of the catheter without sensors was chosen to steer the catheter into the right or left main stem bronchi. The extent of steerability of the catheter is desired to be $20^{\circ}$, as the right bronchus is known to make an angle of $20^{\circ}-30^{\circ}$ with the vertical plane [29]. The trained SMA actuator was bonded to the free length of the catheter on either side. To calculate the bending force generated by the SMA actuator, we increased the current flowing through the SMA until we obtained an actuation of $20^{\circ}$ at $0.8 \mathrm{~A}$.
Assuming Young's modulus $(E)$ of the catheter to be that of the FPCB composing of predominantly polyimide, and the force generated by the SMA to be a uniform load, we calculated the force per unit length $(w)$ using the equation (1),

$$
\theta=\frac{w L^{3}}{6 E I}
$$

where $L$ is the free length, $I$ is the area moment of inertia of the catheter, $E=2700 \mathrm{MPa}$. The force per unit length on the catheter was found to be $0.0113 \mathrm{~N} \mathrm{~mm}^{-1}$ or approximately $0.0678 \mathrm{~N}_{\text {turn }}{ }^{-1}$ based on the calculations. The displacement $(\delta)$ of the distal tip of the free length is calculated to be $6.54 \mathrm{~mm}$ using the equation (2),

$$
\delta=\frac{w L^{4}}{8 E I} .
$$

The calculated displacement is close to the experimentally obtained displacement of $7 \mathrm{~mm}$. Figure 4(D) depicts the antagonistic assembly of the two helical spring actuators.

\subsection{Signal conditioning module}

The MEMS-based thermal flow sensors fabricated using platinum are biocompatible with high physical and chemical stability and repeatable characteristics. The fabricated microheaters and temperature compensation sensors were operated at a constant $70{ }^{\circ} \mathrm{C}$ temperature using the closed-loop feedback circuit (figure 5(A)). 


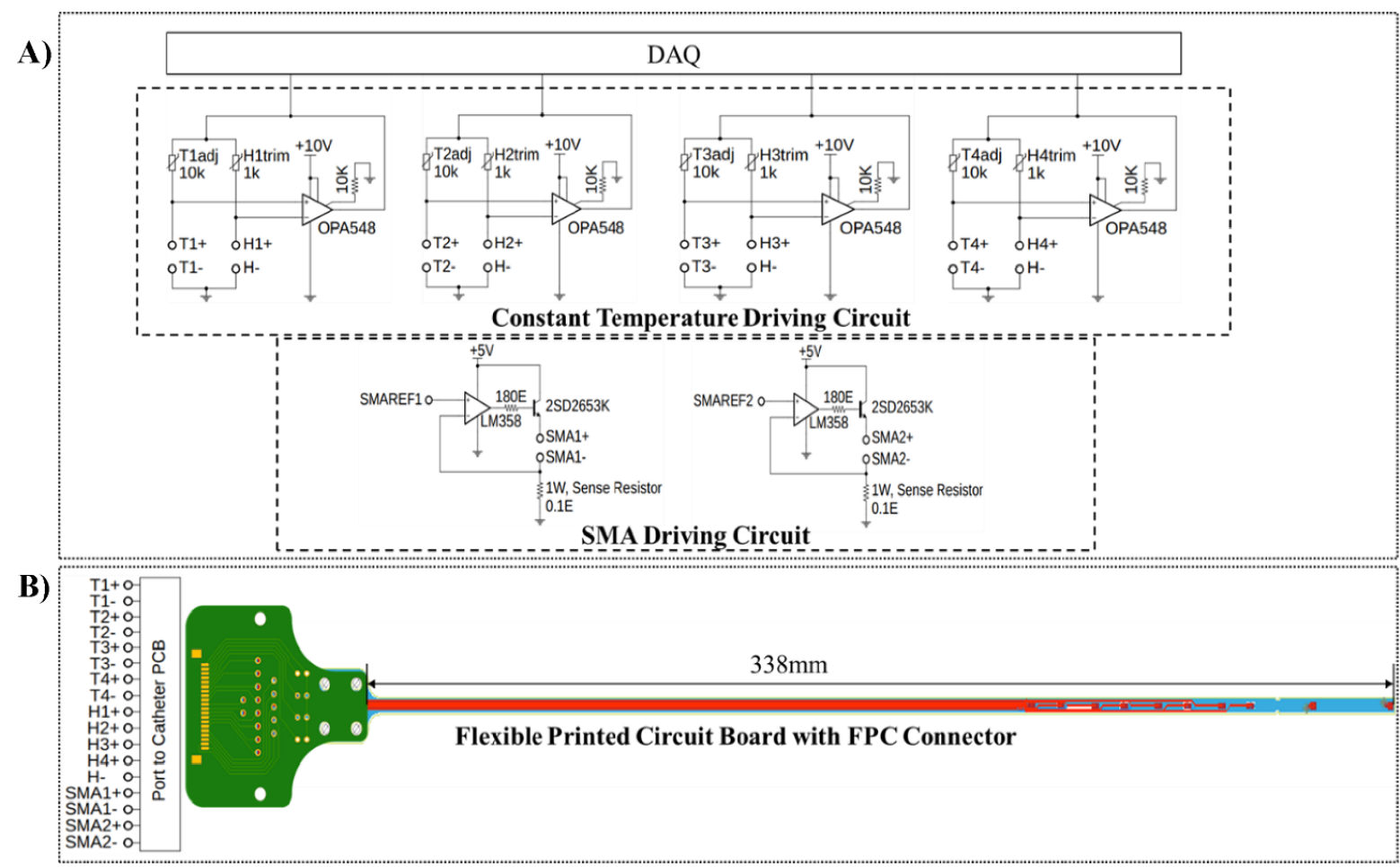

Figure 5. (A) Signal conditioning circuit with four CTA driver circuits and two SMA current drive circuits, (B) the flexible PCB with a breakout board having 20 pin FPCFFC connector.

Any fluid flow across the heater reduces its surface temperature due to convective heat transfer to the fluid, thereby decreasing resistance. The feedback circuit is designed to maintain resistance $\left(R_{\mathrm{h}}\right)$ constant; hence the amplifier drives the differential voltage back into the loop, increasing the current through the resistor. The power driven into the sensor is equal to the power loss due to convective heat transfer (equation (3)),

$$
\frac{V_{\mathrm{h}}^{2}}{R_{\mathrm{h}}}=h A_{\mathrm{h}}\left(T_{\mathrm{h}}-T_{\mathrm{f}}\right)
$$

where $V_{\mathrm{h}}$ is the voltage across the microheater with resistance $R_{\mathrm{h}}$ and surface area $A_{\mathrm{h}}, h$ is the thermal coefficient, $T_{\mathrm{h}}$ and $T_{\mathrm{f}}$ are the temperature of the microheater and fluid, respectively.

From King's law, the equation governing thermal coefficient $(h)$ and fluid velocity $\left(V_{\mathrm{f}}\right)$ is

$$
h=a+b V_{\mathrm{f}}^{\mathrm{c}}
$$

where $a=3.03, b=1.7$ and $c=0.5$, constants obtained from calibration experiments.

For a balanced Wheatstone's bridge with driving voltage $V_{\mathrm{d}}$ and resistance $R_{1}$ connected in series to $R_{\mathrm{h}}$ (equation (5)),

$$
V_{\mathrm{h}}=V_{\mathrm{d}} R_{\mathrm{h}} /\left(R_{1}+R_{\mathrm{h}}\right) \text {. }
$$

From the above equations, fluid velocity $\left(V_{\mathrm{f}}\right)$ can be determined using driving voltage $V_{\mathrm{d}}$ as shown below,

From equation (3),

$$
h=\frac{V_{\mathrm{h}}^{2}}{R_{\mathrm{h}} A_{\mathrm{h}}\left(T_{\mathrm{h}}-T_{\mathrm{f}}\right)} .
$$

Substituting for $V_{\mathrm{h}}$ from equation (5) in equation (6),

$$
h=\frac{V_{\mathrm{d}}^{2} R_{\mathrm{h}}}{A_{\mathrm{h}}\left(T_{\mathrm{h}}-T_{\mathrm{f}}\right)\left(R_{1}+R_{\mathrm{h}}\right)} .
$$

From equation (4),

$$
V_{\mathrm{f}}=\left\{\frac{1}{b}[h-a]\right\}^{\frac{1}{c}}
$$

Substituting for $h$ in equation (8),

$$
V_{\mathrm{f}}=\left\{\frac{1}{b}\left[\frac{V_{\mathrm{d}}^{2} R_{\mathrm{h}}}{A_{\mathrm{h}}\left(T_{\mathrm{h}}-T_{\mathrm{f}}\right)\left(R_{1}+R_{\mathrm{h}}\right)^{2}}-a\right]\right\}^{\frac{1}{c}} .
$$

The higher the fluid velocity, higher is the differential voltage driven into the bridge due to the positive TCR $\left(R_{\mathrm{h}}\right)$. The connections from surface mount sensors from the FPCB to the bridge were made using 20 pin, $0.5 \mathrm{~mm}$ pitch FPCFFC connector, and cable (figure 5(B)). Table 2 describes the fabrication costs and materials used to fabricate the intubation catheter.

\subsection{Test-bench with excised tissue}

To study the fabricated catheter, excised tracheal tissues from sheep were obtained from a government-approved slaughterhouse. Biosafety clearance (IBSC/IISc/HP/09/2019) and Ethical Committee clearance (CAF/Ethics/676/2019) 
Table 2. Intubation catheter features.

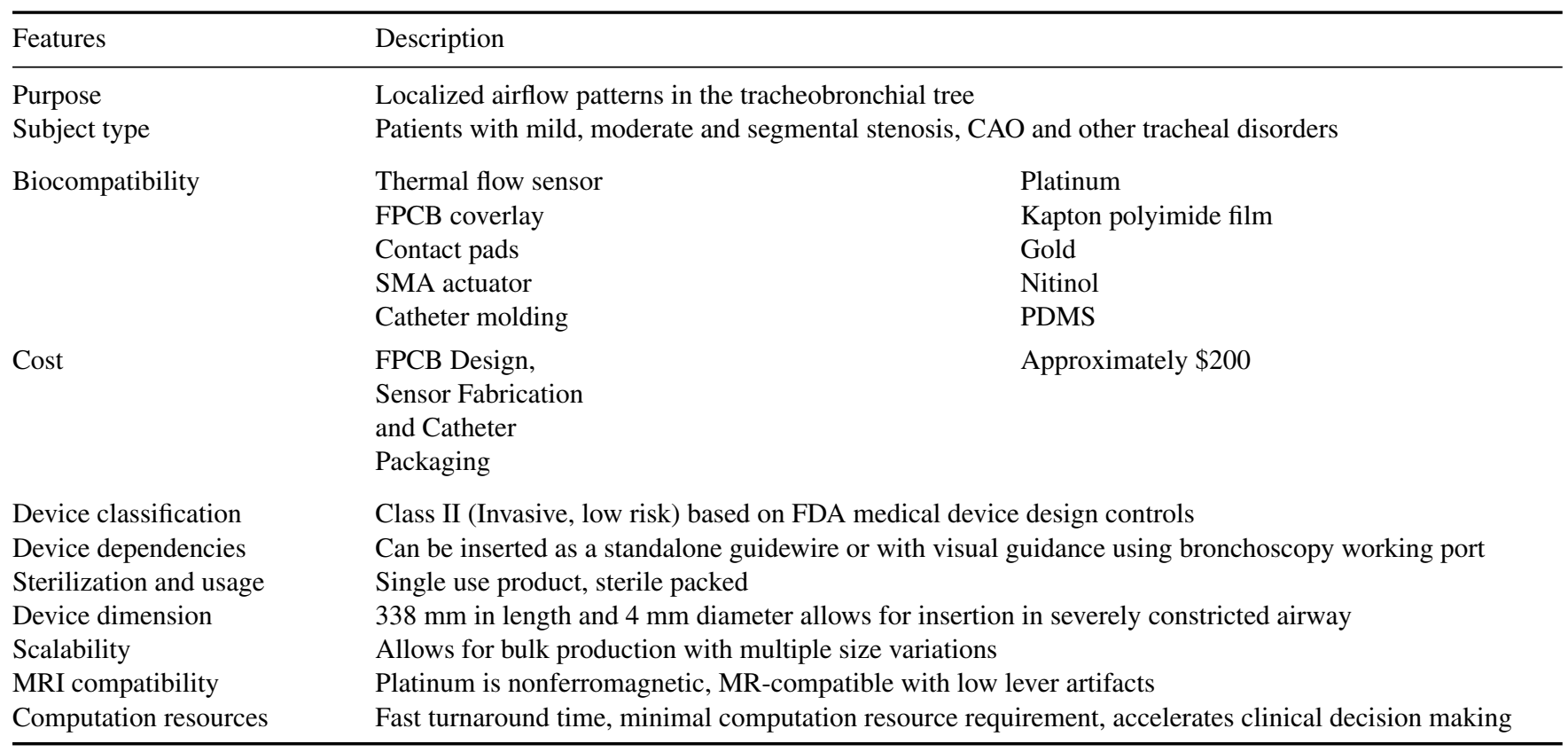

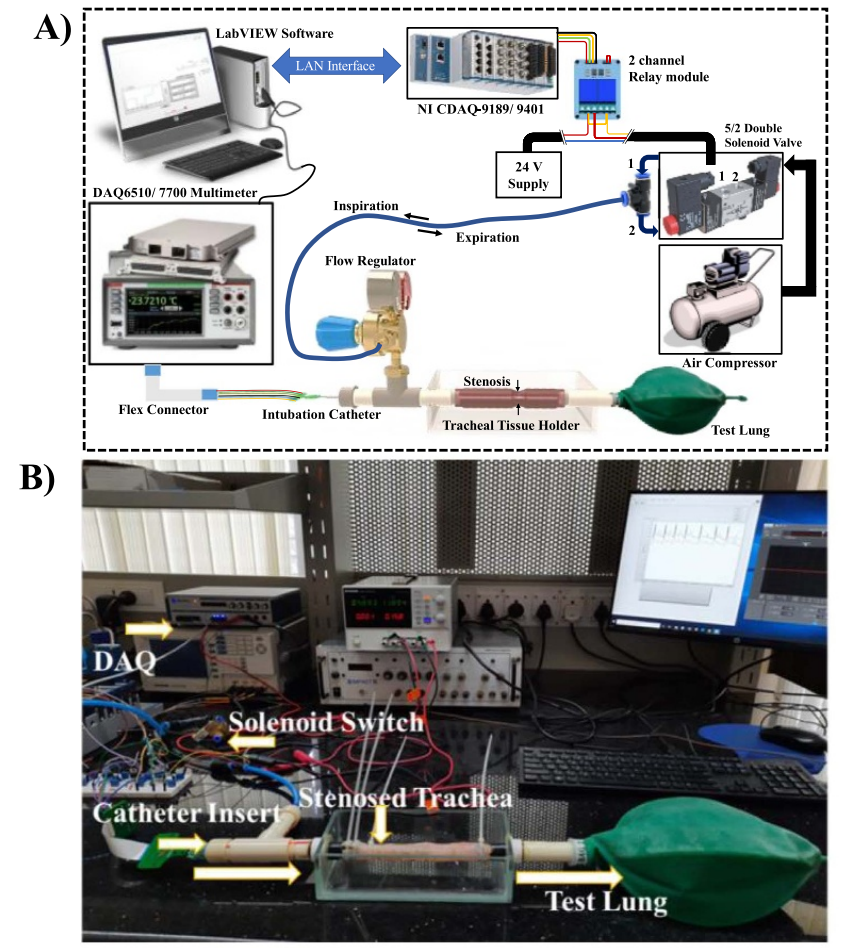

C)

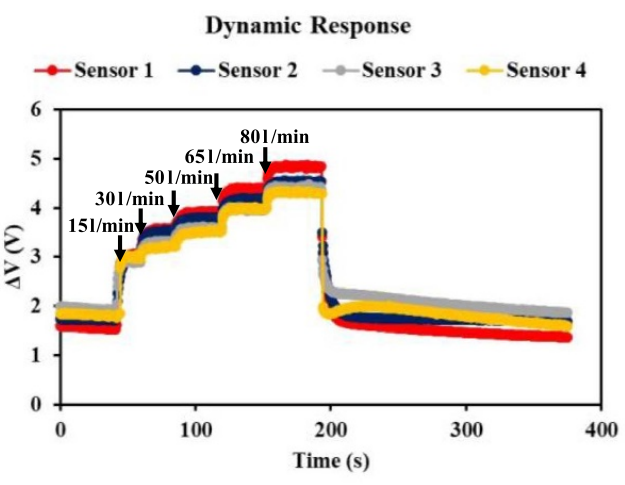

D)

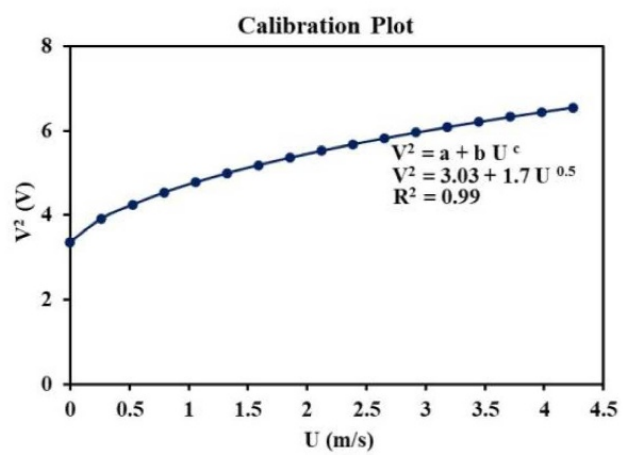

Figure 6. (A) Schematic of the test-bench designed to investigate tracheal disorders, (B) experimental workstation, (C) dynamic response characterization of the fabricated sensors, and (D) calibrating the sensors using known fluid velocity.

is obtained from the Institutional Animal Ethics Committee (Reg.No:48/GO/Re-SL/Bi-S/99/CPCSEA). The testbench includes a computer workstation connected to a data acquisition system (Keithley 7700 Differential multiplexer module) and a signal conditioning board (figure 6(A)). Dataacquisition and system control was established using LabView programming (shown in supplementary information figure S1 (available online at stacks.iop.org/JMM/31/055007/mmedia)). The excised tissue was held in a custom-built trachea holder with an inlet connected to an air compressor unit with a filterregulator-lubricator connector, and the tissue holder's outlet is connected with a reservoir bag (figure 6(B)) to mimic the lung. As discussed before, an adult trachea is $1.8-2 \mathrm{~cm}$ in diameter, $15 \mathrm{~cm}$ in length with $1 \mathrm{~mm}$ wall thickness. Although, the trachea spits into a right and left bronchus that further progresses into the lung, our pseudo-physiological test-bench comprises of a tracheal holder with a reservoir bag having dimensions close to real anatomical geometry. The 21 
reservoir bag closely mimics the lung as it is commonly used in the mechanical ventilation system to deliver desired tidal volume and pressure [30]. A solenoid valve was used to switch between the inspiration and expiration cycles. The rise and fall time for varying flow rates at $70{ }^{\circ} \mathrm{C}$ sensor operating temperature is $1.5 \mathrm{~s}$ and $0.5 \mathrm{~s}$, respectively. The dynamic response curve is shown in figure 6(C). A pitot tube calibration set-up was used to determine the sensor working voltage range corresponding to known velocities. The sensor voltage response for fluid velocity ranging from 0 to $4.2 \mathrm{~m} \mathrm{~s}^{-1}$ was recorded, and corresponding calibration constants $a, b$, and $c$ are determined (figure 6(D)).

\section{Results and discussion}

The fabricated catheter was advanced through the lumen, and the corresponding voltage $(\Delta V)$ were recorded. The sensor voltage $\left(V_{\mathrm{h}}\right)$, under no flow was set at $1.4 \mathrm{~V}$. The data was recorded at 15, 30, 50, 65, and $801 \mathrm{~min}^{-1}$. Flow rates, 65 and $801 \mathrm{~min}^{-1}$ are very high compared to ideal airflow conditions; however, experiments were conducted to see the impact of turbulence flow on sensor output under normal and stenosed conditions. The tracheal tissue (\#Tissue 1) measured $15 \mathrm{~mm}$ in length with $1.8 \mathrm{~mm}$ wall thickness. Patency was calculated after subtracting the wall thickness from the corresponding outer diameter (OD). The OD was measured for the proximal, medial, and distal trachea (figure 7(A)). As the microheaters were operated at $70{ }^{\circ} \mathrm{C}$, the impact of temperature on tissue surface is vital.

The catheter with microheaters and a simplified geometry of the trachea was created in COMSOL Multiphysics ${ }^{\circledR}$, while assigning the material property of the tissue and the siliconbased platinum microheater. A laminar flow interface was used to set the airflow inside trachea using the inlet boundary condition on one side with $0.8 \mathrm{~m} \mathrm{~s}^{-1}$ normal inflow velocity. The outlet boundary condition was applied to the other end of the trachea. The tracheal wall was set to no slip boundary condition. The electrical component of the microheater was modelled using the electric currents, shell (single layer) interface. The electric potential boundary condition was applied to one end of the microheater, while the other end was grounded. The simulation was performed by driving the microheater at $1.4 \mathrm{~V}$. The heat transfer in solid and fluid interface was used to model the temperature variation within the channel. The heat flux boundary condition was applied on the outer walls of the tracheal with heat transfer coefficient of $2 \mathrm{~W} \mathrm{~m}^{-2} \mathrm{~K}^{-1}$. The heat generated by the microheater due to Joule Heating was coupled with the heat transfer in solid and fluid interface using the boundary electromagnetic heat source interface. The laminar flow interface was coupled with the heat transfer in solid and fluid interface using the Multiphysics non-isothermal flow interface.

A physics-controlled mesh which automatically meshes based on the physics being solved was used. This automatically takes care of the boundary layer mesh required for the fluid flow physics. The model with around one million DOF was solved using a computer having $32 \mathrm{~GB}, 3.70 \mathrm{GHz}$ Intel Xeon processor with 64-bit operating system. The overall simulation time was $1582 \mathrm{~s}$ (26 min, $22 \mathrm{~s}$ ) consuming 4.46 GB Physical memory and 6.16 GB of Virtual memory. The temperature distribution profile (figure 7(B)) shows an exponentially decreasing temperature pattern from the centerline to the tissue surface. Also, the mechanism of convective heat transfer from the microheater to the fluid ensures no thermal damage to the tissue walls.

Experiments were performed immediately after procuring the tissue from the slaughterhouse. The blood and skin from the tissue surface was cleaned and then fixed in the tissue holder. Airflow was generated at a controlled rate using the air compressor. The $\Delta V$ for all four sensors at $151 \mathrm{~min}^{-1}$ was recorded. The experiment was repeated for $30,50,65$, and $801 \mathrm{~min}^{-1}$ (figure 7(C)). At 15 and $301 \mathrm{~min}^{-1}$, the $\Delta \mathrm{V}$ had a standard deviation (SD) of $0.003 \mathrm{~V}(0.1 \% \mathrm{RMS}$ error) and at higher flow rates, the SD was $0.02 \mathrm{~V}(0.6 \%$ RMS error). The average CSA of the trachea under normal condition is $314 \mathrm{~mm}^{2}$. The airflow pattern is uniform across the complete segmental length for all the flow rates (figure 7(D)). After obtaining data for a normal condition, a zip-tag is used to induce stenosis in the proximal region. The stenosed segment now has a $10 \%$ reduction in CSA from the original. By flowing controlled air, $\Delta \mathrm{V}$ was measured for all four sensors (figure $8(\mathrm{~A})$ ). For all five experimental flow rates, relatively higher voltage peaks from the sensor 1 was observed. This can be attributed to the fact that sensor 1 is in close proximity to the site of obstruction. The flow pattern has a peak and then gradually decreases as it progresses towards the trachea's distal end (figure 8(B)). Following Bernoulli's fluid dynamics principle, the fluid gains momentum as channel CSA reduces, this increases velocity in the stenosed region. Higher the fluid velocity, higher will be the convective heat transfer from the microheater to the fluid. Since the microheater was designed to operate at constant temperatures, to compensate for the cooling effect, the feedback circuit drives higher currents to reset the operating temperature of the microheater. Thus, with reduced CSA we see an increase in sensor voltage change compared to normal conditions. The distance between the fourth sensor and the SMA actuator is designed to have a $20 \mathrm{~mm}$ gap and the inter-sensor gap is $10 \mathrm{~mm}$. Any artifacts in the airflow due to bending of the SMA actuator was found to be negligible as the disturbance dies as it flows downstream over the $20 \mathrm{~mm}$ long gap (shown in supplementary information figure S2).

At 15 and $301 \mathrm{~min}^{-1}, \Delta V$ had a SD of $0.005 \mathrm{~V}(0.2 \%$ RMS error) and the higher flow rates had SD of $0.02 \mathrm{~V}$ ( $0.5 \%$ RMS error). As the sensor position on the catheter is known, the peaks generated in the pattern can give a reasonable estimate of stenosis location. We perform experiments by inducing the second stenosis that is $18 \mathrm{~mm}$ away from the first stenosis. Average CSA of the second stenosed segment was $14 \%$ reduced from the original area. From 15 to $801 \mathrm{~min}^{-1}, \Delta \mathrm{V}$ of sensor 1 and sensor 2 were $1.5 \times$ and $1.7 \times$ higher than their voltage changes under normal conditions (figure $8(\mathrm{C})$ ).

The flow patterns generated using each sensor data for all experimental flow rates shows two significant peaks 


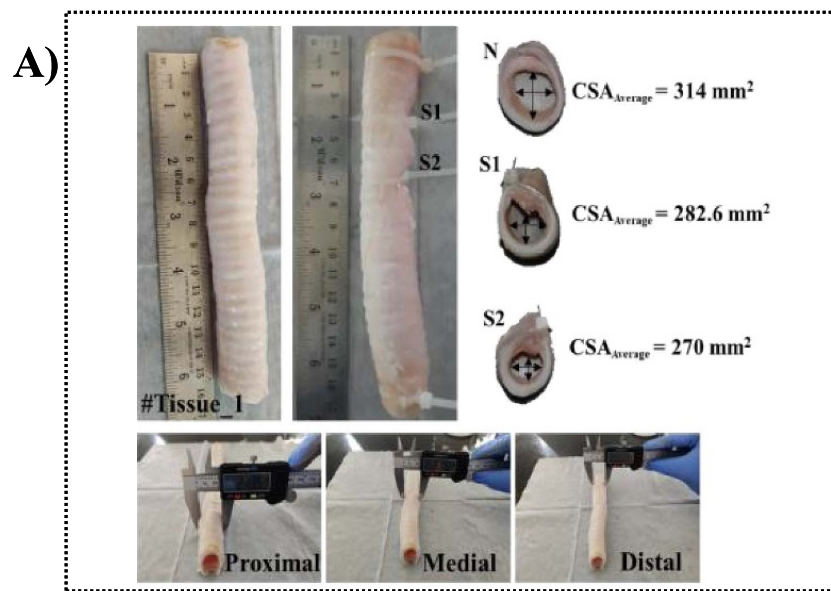

C)

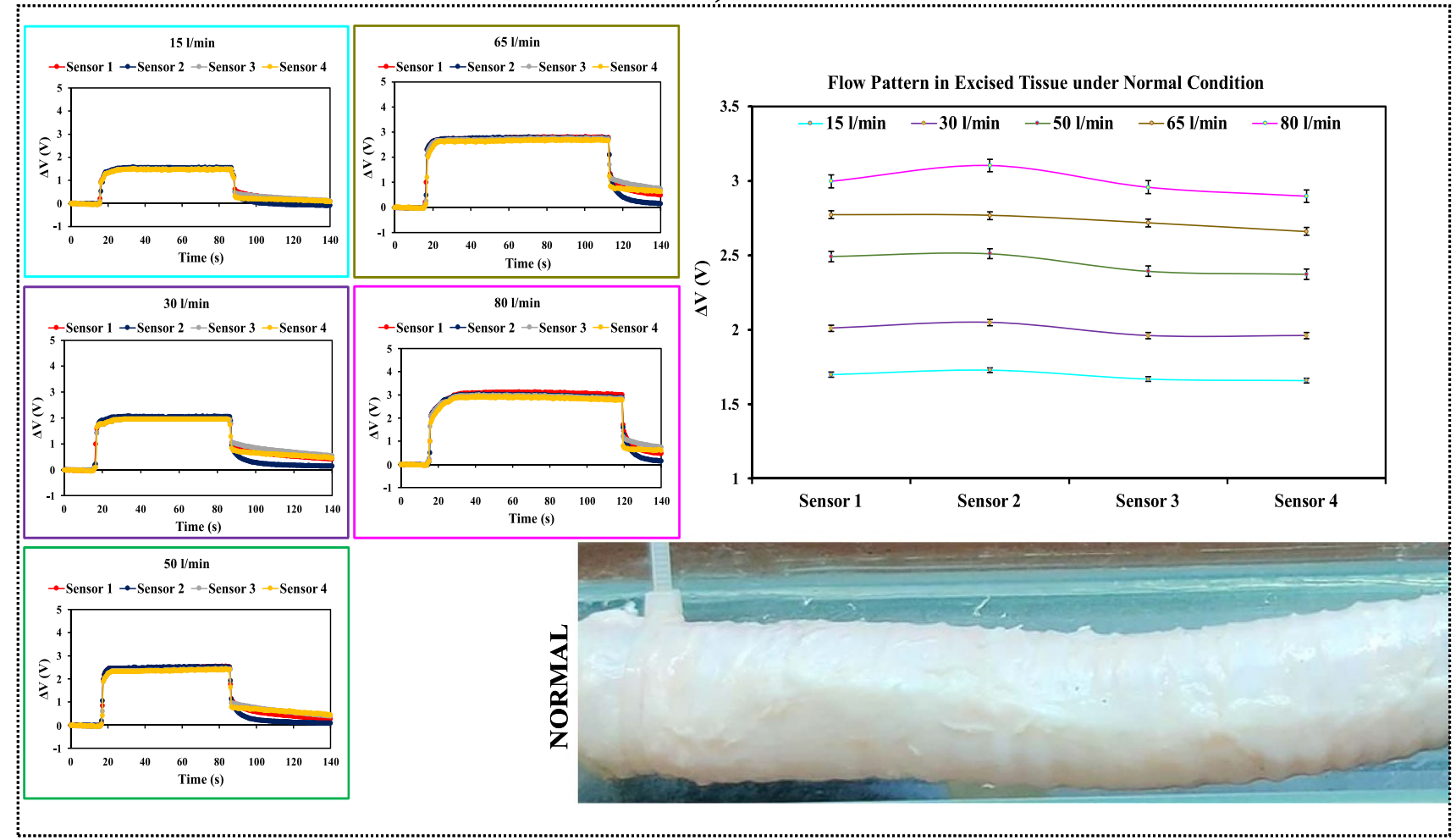

B)

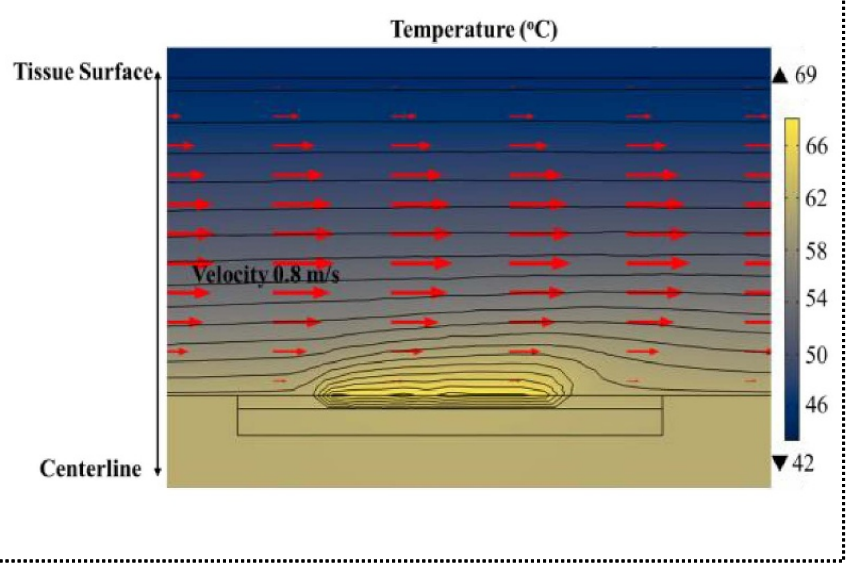

D)

Figure 7. (A) Excised tissue measurements; (B) temperature profile from centerline to tissue wall; (C) represents sensor voltage plots for multiple volumetric flow rates and (D) represents flow pattern for normal tissue.

(figure 8(D)). At 15 and $301 \mathrm{~min}^{-1}, \Delta V$ has a SD of $0.01 \mathrm{~V}$ (0.39\% RMS error) and higher flow rates have SD $0.02 \mathrm{~V}$ ( $0.5 \%$ RMS error). Although the peaks correspond to the magnitude of reduced CSA, we speculate that the second peak with a higher magnitude is a cumulative effect of both the stenosis. The velocity gained by the fluid at first stenosis encounters another constriction in a close instant of time; hence a turbulence may be created, which contributes to the higher magnitude of $\Delta V$ in sensor 2 . To test the hypothesis, we performed an experiment with a newly excised tissue by simulating three stenosis (figure 9(A)). The first constriction contributes for the increase in voltage peak of sensor 1 . The rise in sensor 2 voltage is not only dominated by the constriction but also sees a contribution from the previously constricted site. Adding another stenosis in close proximity to the second is effectively increases the stenotic segment length and contributes to the rise in peak in the third sensor (figure 9(B)). The experiment was conducted only for 15,30 and $501 \mathrm{~min}^{-1}$ flows as the tracheal diameter was only $12 \mathrm{~mm}$ and could not withstand higher flow rates.

From the flow patterns generated using the sensor array, the catheter demonstrates its potential use in multi-segmental tracheal stenosis having mild and moderate constrictions.

\subsection{Blind test for pulsatile flow}

We performed experiments using another tracheal tissue with an average CSA of $15.2 \mathrm{~mm}^{2}$ (figure 10(A)). The catheter 
A)
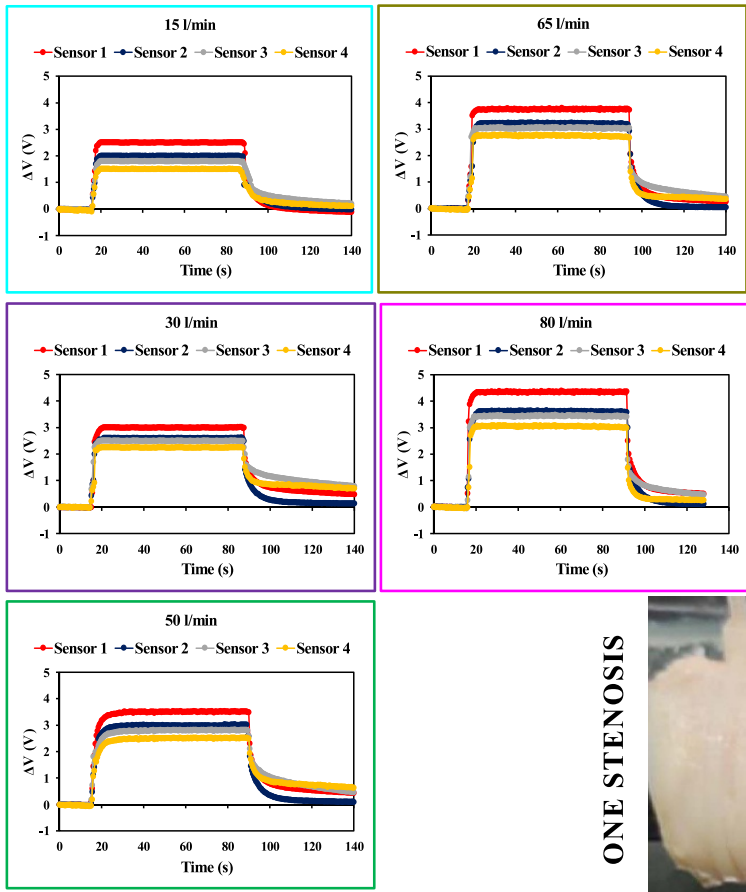

C)
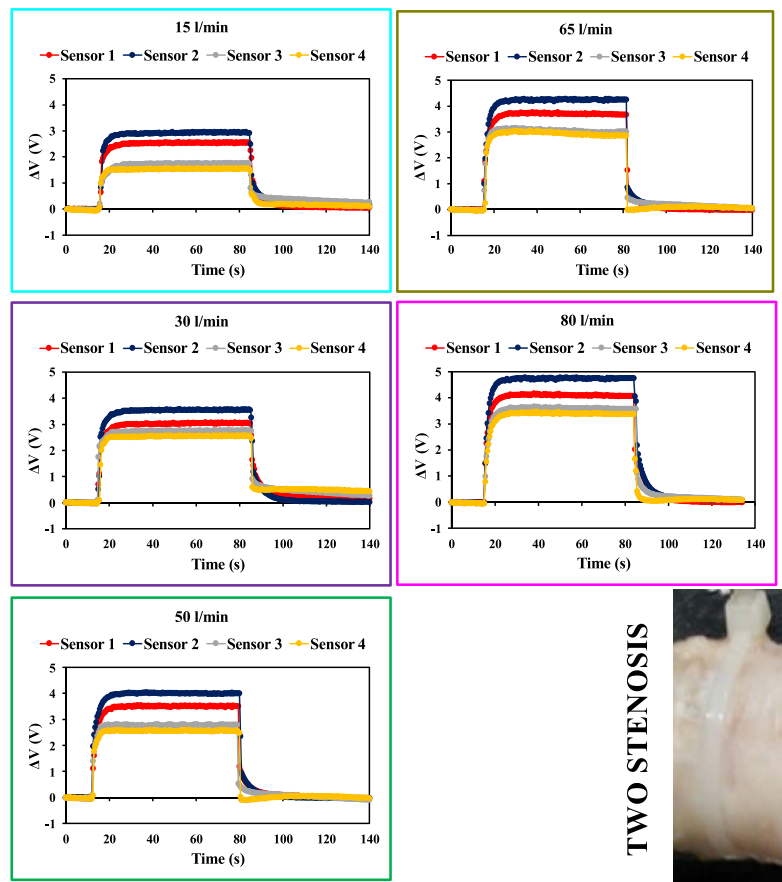

\section{B)}
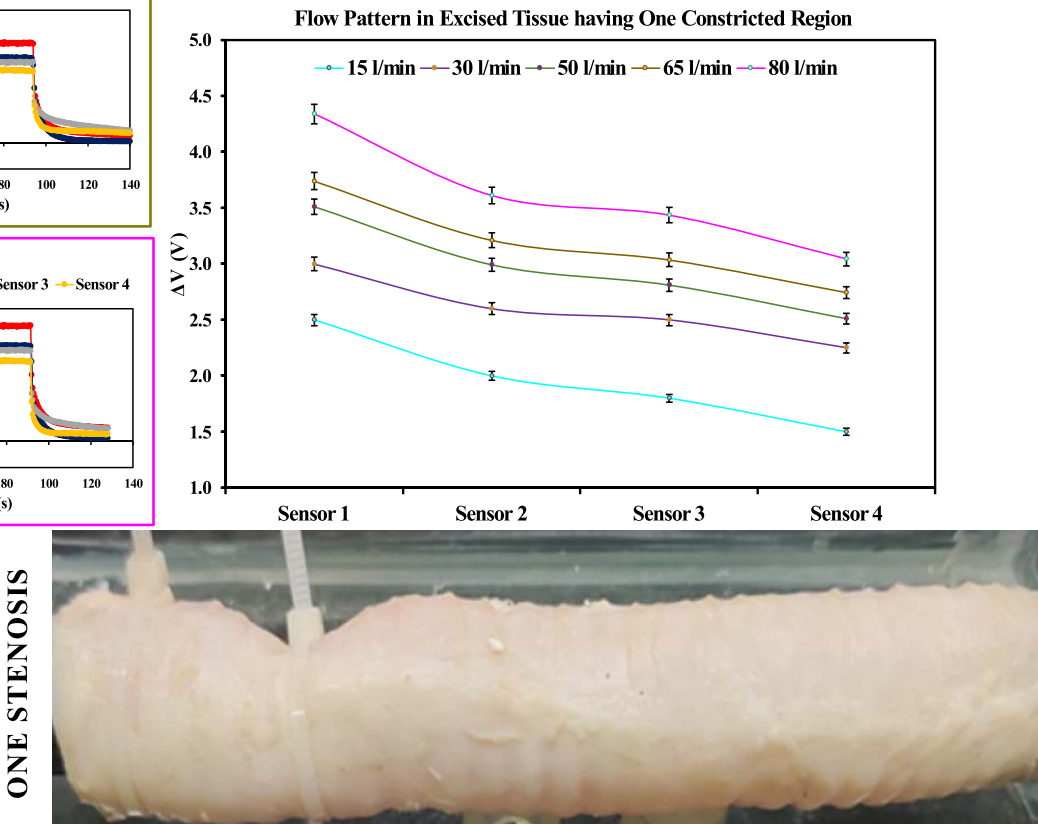

D)
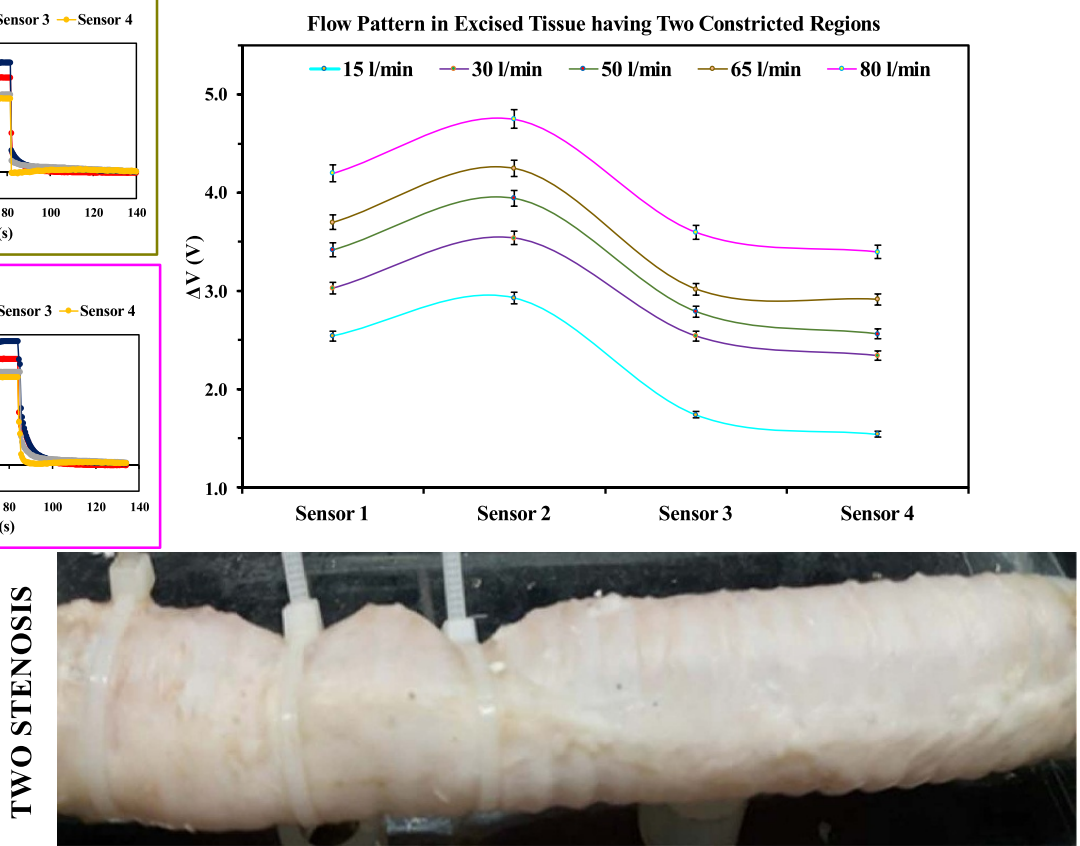

Figure 8. (A), (C) Represent sensor voltage plots for a stenosed and two segment stenosed tissue for multiple volumetric flow rates; and (B), (D) represent the corresponding flow pattern obtained in single stenosed and two segment stenosed tissue.

was advanced through the stenosed segment, and the compressor was operated to flow air at $301 \mathrm{~min}^{-1}$. The solenoid switch controls the fluid flow through a T-junction connector with inlet and outlet ports. The solenoid switch was on for the inspiration cycle, and the air flows from the compressor through the inlet port into the trachea and the reservoir bag.
The voltage readings from the sensors are recorded and converted to velocity using equation (6). The solenoid valve was turned off to simulate expiration, and the air from the reservoir bag flows into the trachea and floods through the output port. The cyclic pattern observed for all four sensors under normal tissue conditions is shown in figure 10(B). The inspiration 


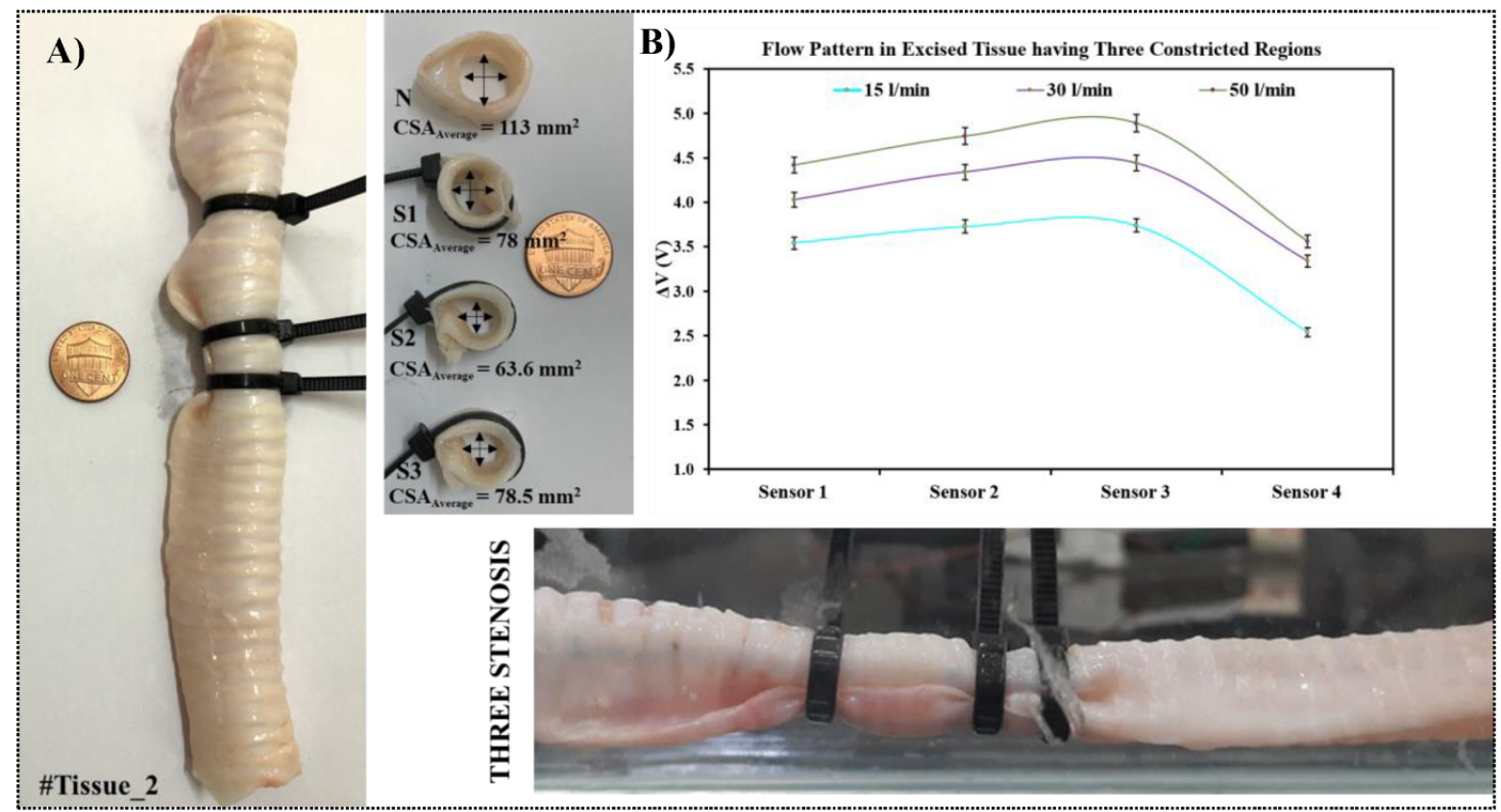

Figure 9. (A) Excised tissue measurements; (B) represents flow pattern obtained using the tissue at multiple volumetric flow rates with three segmental stenosis.

peaks for all four sensors were consistent with an average velocity of $0.8 \mathrm{~m} \mathrm{~s}^{-1}$, and expiration peaks were at an average of $0.24 \mathrm{~m} \mathrm{~s}^{-1}$. The difference in magnitude was because the air compressor is an active source that floods air at high pressure; however, the reservoir bag behaves like a passive source and floods air at relatively lower pressure. Another observation from the flow patterns was the broad bandwidth of the inspiration and expiration cycle. The sensors' response time was reasonably good; however, the long channel length from source to the point of interest contributes to the delay in pulsatile flow. The identical peaks across four sensors correspond to the uniform tracheal diameter.

The effective tracheal CSA was reduced by $50 \%$ at the proximal region, and the corresponding regional velocity plots is shown in figure $10(\mathrm{C})$. Only sensor 2 has dominant peaks with average velocity in the inspiration cycle measuring $2 \mathrm{~m} \mathrm{~s}^{-1}$ and $0.52 \mathrm{~m} \mathrm{~s}^{-1}$ in the expiration phase. The magnitude of other sensors in the array measures an average of $0.8 \mathrm{~m} \mathrm{~s}^{-1}$ for inspiration and $0.23 \mathrm{~m} \mathrm{~s}^{-1}$ in the expiration cycle. The catheter was slightly pushed forward, and the experiment was repeated. The data obtained from the catheter in the new position is shown in figure 10(D). Sensor 3 has the highest magnitude in the inspiration phase, measuring $1.8 \mathrm{~m} \mathrm{~s}^{-1}$ and sensor 2 with the highest magnitude in the expiration phase, measuring the magnitude of $0.59 \mathrm{~m} \mathrm{~s}^{-1}$. The flow pattern implies stenosis was in between sensors 2 and 3. Manoeuvring the catheter at different positions can precisely locate the site of obstruction as the sensor output corresponds to the local CSA.

CFD based studies have shown pressure drop and velocity measurements only when lumen obliteration is higher; however, the catheter performance could be evaluated even for a mild obliteration in excised tissue. The challenges encountered with CFD simulations are resolving turbulence for higher flows and build-time for each patient-centric model, extending from several hours to even days with dependencies such as accuracy of meshing strategies. Large, randomized trials to determine the best strategy for evaluating and treating the patient population are extremely difficult using simulation studies. Hence the catheter can be used as a supplement to existing technology to determine pre- and post-operative surgical outcomes.

The observation made from the flow pattern is that for stenosed segments, error increases for higher flow rates. As constriction increases the regional turbulence, the high Reynolds number 2673 (considering air density $1.225 \mathrm{~kg} \mathrm{~m}^{-3}$ and viscosity $18.1 \mu \mathrm{Pa} \mathrm{s}$ ), creates a high-velocity jet of air, causing redistribution of flow at the stenosed region. At higher volumetric flows (50, 65 and $801 \mathrm{~min}^{-1}$ ), velocity increases proportionally. The spike in velocity at the stenosed region at higher volumetric flows is not only because of the reduced CSA but also sees a contribution from the vortex formed due to increase in turbulence. The randomness in flow at higher flow rate contributes to an increase in error.

The peaks, however, correlate with the site of obstruction and degree and stenosis. Hence this data can be used for targeted clinical treatment. The latency in pulsatile flow is due to the length of pneumatic pipes connected between the compressor and reservoir. The lag can thus be reduced by optimizing the test-bench set-up. To comply with clinical standards and proper stricture classification, the source and sink pressure need to comply with the actual ventilator standards.

Clinical translation often demands for Proof-of-concept validation in animal models, hence performing in vivo 
A)

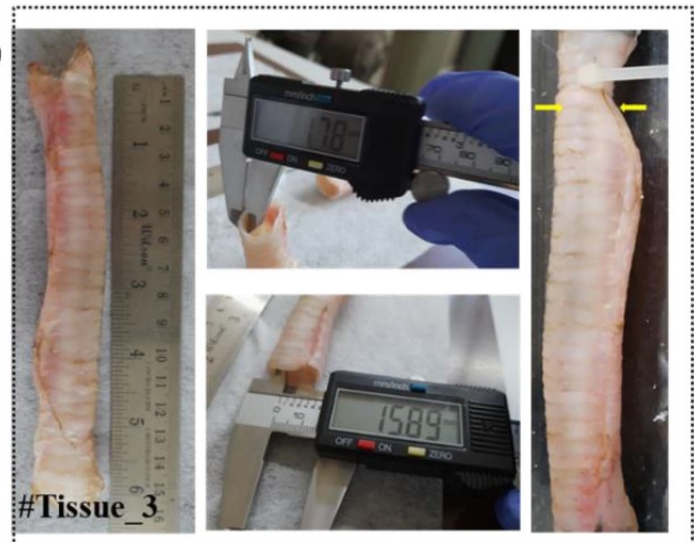

B)

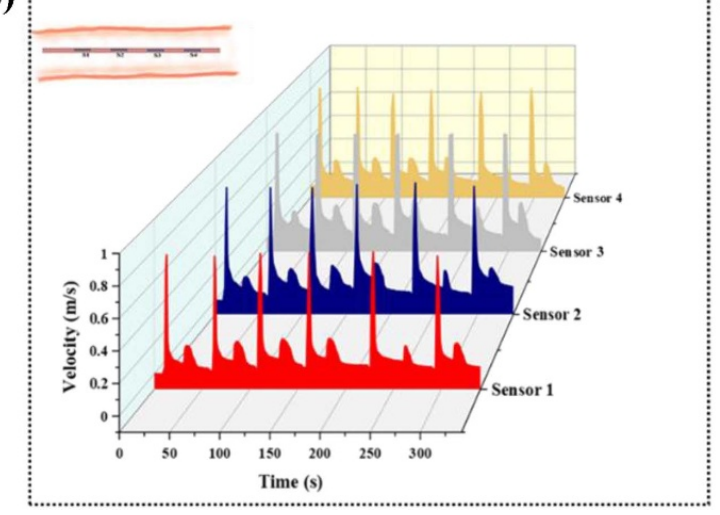

C)

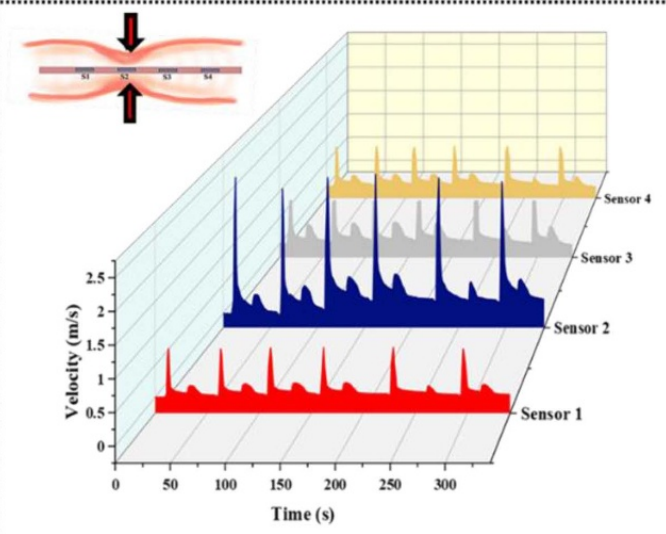

D)

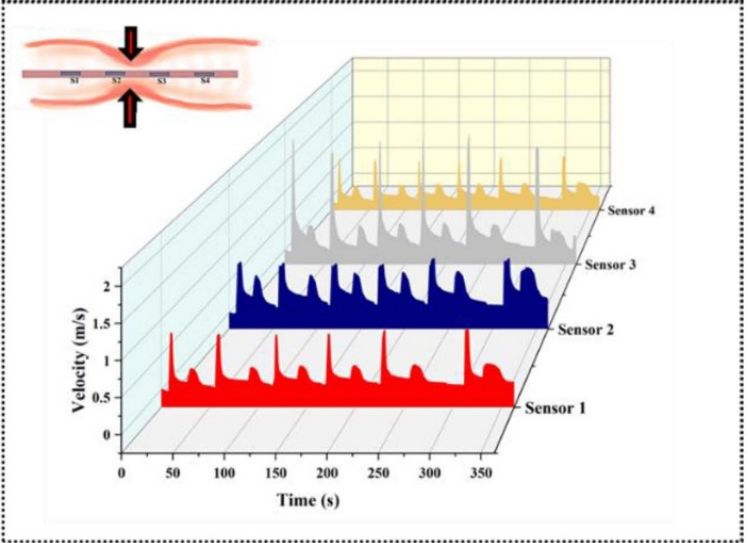

Figure 10. (A) Excised tissue measurements of test sample 3, velocity plots generated from each sensor data for: (B) normal tissue, (C) sensor positioned exactly below stenosis, and (D) stenosis in between two sensors.

experiments is the way forward to validate the use of the intubation catheter. To study the health and disease condition of the airway, research groups have performed experiments on canines with induced tracheal stenosis [31], porcine tracheal tissues [32], rabbits [33] and sheep [34]. We envisage performing in vivo experiments using sheep models because their comparable airway anatomical structure with humans and their large tracheal diameters makes it most favorable for respiratory intervention studies [35]. Once the animal is restrained, either with a laryngoscope and/or after endotracheal tube (ETT) insertion, the catheter can be advanced through the working channel port available in the Bronchoscope or can be introduced like the bougie guidewire, through the mouth, larynx, and into the tracheo bronchial tree.

Stenosis can be artificially induced by increasing the cuff pressures higher than normal $\left(20-30 \mathrm{~cm} \mathrm{H}_{2} \mathrm{O}\right)$. Larger ETT size and higher cuff pressures can be adopted to simulate tracheal stenosis. The localized airflow patterns in healthy and stenosed conditions can be generated using the intubation catheter. For integration in a clinical setting, the catheter system design can be made more robust by using a $\mathrm{PSoC}^{\circledR}$ microcontroller module with inbuilt BLE (Bluetooth Low Energy) and IDACs (Current Digital to Analog Converters) for wireless data transmission. Thus, the proposed system has a good scope for portability with effective bench-to-bedside translation.

\section{Conclusion}

This study demonstrates an intubation catheter's design and development with integrated flow sensors, sub-millimeter helical shape-memory actuators, and a test bench to simulate airflow patterns in stenosed tracheal pathologies. The sensors and actuators are mounted on an FPCB, which augments catheter flexibility and can be introduced through complex airway anatomy. Experiments are conducted with excised sheep tracheal tissues, and the impact of flow distribution on stenosed trachea with $10 \%, 15 \%$ and $50 \%$ reduction in patency is observed. The small catheter diameter allows for easy advancement through the site of obstruction. The flow patterns generated by the catheter show uniform distribution through the normal airway and a spike in velocity corresponding to the site of obstruction in the stenosed airway. The tool can add considerable value to interventional bronchoscopists as stenosis can be detected at a precritical stage. The study further provides insight into flow patterns in varying grades of tracheal stenosis and the impact of multisegmental stenosis. The experimental set-up can be used for understanding complex tracheal disorders and can be extended towards identifying the dependence of flow patterns with age, various parameters that affect flow dynamics, the impact of stent size and its positioning, the nature and performance of tissue grafts, etc. A thorough understanding of the influence of these parameters 
can expedite on-site decision making and suggest alternatives to existing guidelines.

\section{Data availability statement}

All data that support the findings of this study are included within the article (and any supplementary files).

\section{Declaration}

We confirm that all the experiments conducted for this work abide with the principles outlined in the Institutional Animal Ethics Committee (Reg.No:48/GO/Re-SL/BiS/99/CPCSEA). The approval ID for institutional biosafety clearance and ethical committee clearance obtained for this work are IBSC/IISc/HP/09/2019 and CAF/Ethics/676/2019.

\section{ORCID iDs}

V Bhushan (D) https://orcid.org/0000-0001-5197-1286 Kevin Abishek (D) https://orcid.org/0000-0002-8455-4865 Sanjay Rao (D) https://orcid.org/0000-0003-0407-7067 Yeongjin Kim (D) https://orcid.org/0000-0001-5130-001X Hardik J Pandya (D) https://orcid.org/0000-0003-3498-6894

\section{References}

[1] De S and De S 2008 Post intubation tracheal stenosis Indian J. Crit. Care Med. Peer-Rev. Off. Publ. Indian Soc. Crit. Care Med. 12 194-7

[2] Zias N, Chroneou A, Tabba M K, Gonzalez A V, Gray A W, Lamb C R, Riker D R and Beamis J F 2008 Post tracheostomy and post intubation tracheal stenosis: report of 31 cases and review of the literature BMC Pulm. Med. 818

[3] Santiago-Rosado L M, Sigmon D F and Lewison C S 2020 Tracheal trauma StatPearls PMID: 29763191 (Treasure Island, FL: StatPearls Publishing) (available at: www.ncbi. nlm.nih.gov/books/NBK500015/)

[4] Yokoi A 2018 Congenital tracheal stenosis: what should we look at for successful tracheoplasty? Transl. Pediatr. $7229-32$

[5] Sengupta A and Murthy R A 2020 Congenital tracheal stenosis \& associated cardiac anomalies: operative management \& techniques J. Thorac. Dis. 1210

[6] Barros Casas D, Fernández-Bussy S, Folch E, Flandes Aldeyturriaga J and Majid A 2014 Non-malignant central airway obstruction Arch. Bronconeumol. Engl. Ed. $50345-54$

[7] Oberg C, Holden V and Channick C 2018 Benign central airway obstruction Semin. Respir. Crit. Care Med. $39731-46$

[8] Mudambi L, Miller R and Eapen G A 2017 Malignant central airway obstruction J. Thorac. Dis. 9 S1087-110

[9] George G and Lippmann M Disorders of the central airways and upper airway obstruction $\mathrm{p} 25$

[10] Harless J, Ramaiah R and Bhananker S M 2014 Pediatric airway management Int. J. Crit. Illn. Inj. Sci. 4 65-70

[11] Ernst A, Feller-Kopman D, Becker H D and Mehta A C 2004 Central airway obstruction Am. J. Respir. Crit. Care Med. 169 1278-97

[12] Handa H, Huang J, Murgu S D, Mineshita M, Kurimoto N, Colt H G and Miyazawa T 2014 Assessment of central airway obstruction using impulse oscillometry before and after interventional bronchoscopy Respir. Care 59 231-40

[13] Shweel M and Shaban Y 2013 Radiological evaluation of post-traumatic tracheal stenosis using multidetector CT with multiplanar reformatted imaging and virtual bronchoscopy: comparison with intraoperative findings Egypt. J. Radiol. Nucl. Med. 44 513-21

[14] Stephens K E and Wood D E 2000 Bronchoscopic management of central airway obstruction J. Thorac. Cardiovasc. Surg. 119 289-96

[15] Maniwa Y 2016 Surgical treatment of air way disease J. Thorac. Dis. 8 E78-82

[16] Harris K, Alraiyes A H, Attwood K, Modi K and Dhillon S S 2016 Reporting of central airway obstruction on radiology reports and impact on bronchoscopic airway interventions and patient outcomes Ther. Adv. Respir. Dis. 10 105-12

[17] Murgu S and Colt H 2013 Subjective assessment using still bronchoscopic images misclassifies airway narrowing in laryngotracheal stenosis Interact. Cardiovasc. Thorac. Surg. 16 655-60

[18] Mimouni-Benabu O, Meister L, Giordano J, Fayoux P, Loundon N, Triglia J M and Nicollas R 2012 A preliminary study of computer assisted evaluation of congenital tracheal stenosis: a new tool for surgical decision-making Int. J. Pediatr. Otorhinolaryngol. 76 1552-7

[19] Brouns M, Jayaraju S T, Lacor C, De Mey J, Noppen M, Vincken W and Verbanck S 2007 Tracheal stenosis: a flow dynamics study J. Appl. Physiol. 102 1178-84

[20] Bates A J, Comerford A, Cetto R, Doorly D J, Schroter R C and Tolley N S 2017 Computational fluid dynamics benchmark dataset of airflow in tracheas Data Brief 10 101-7

[21] Zhu L, Gong X, Liu J, Li Y, Zhong Y, Shen J and Xu Z 2020 Computational evaluation of surgical design for multisegmental complex congenital tracheal stenosis Biomed. Res. Int. 2020 1-10

[22] Chen F-L, Horng T-L and Shih T-C 2014 Simulation analysis of airflow alteration in the trachea following the vascular ring surgery based on CT images using the computational fluid dynamics method J. X-Ray Sci. Technol. 22 213-25

[23] Hollister S J, Hollister M P and Hollister S K 2017 Computational modeling of airway instability and collapse in tracheomalacia Respir. Res. 1862

[24] Noma H, Hasegawa Y, Matsushima M, Kawabe T and Shikida M 2021 Micro-machined stent flow sensor for detecting breathing and heartbeat from airflow in airway of rat J. Micromech. Microeng. 31025006

[25] Kawamoto Y, Maeda Y, Hasegawa Y, Matsushima M, Kawabe T and Shikida M 2021 Development of sensor-probe system with function of measuring flow and pressure for evaluating breathing property at airway in lungs Microsyst. Technol. 1-8

[26] Griscom N and Wohl M 1986 Dimensions of the growing trachea related to age and gender Am. J. Roentgenol. $146233-7$

[27] Tsega E G 2018 Computational fluid dynamics modeling of respiratory airflow in tracheobronchial airways of infant, child, and adult Comput. Math. Methods Med. $20181-9$

[28] Hamilton N J et al 2015 Tissue-engineered tracheal replacement in a child: a 4-year follow-up study Am. J. Transplant. 15 2750-7

[29] Manolakis A, Ionescu C, Cambrea M, Bordei P and Iliescu D 2014 Relations between the tracheal and pulmonary trunk bifurcations ARS Med. Tomitana 20 110-4

[30] Zuckerberg J, Shaik M, Widmeier K, Kilbaugh T and Nelin T D 2020 A lung for all: novel mechanical ventilator for emergency and low-resource T settings Life Sci. 257118113 
[31] Su Z, Li S, Zhou Z, Chen X, Gu Y, Chen Y, Zhong C, Zhong M and Zhong N 2017 A canine model of tracheal stenosis induced by cuffed endotracheal intubation Sci. Rep. 745357

[32] Bu R, Balakrishnan S, Price H, Zdanski C, Mitran S and Oldenburg A L 2019 Localized compliance measurement of the airway wall using anatomic optical coherence elastography Opt. Express 2716751

[33] Zhang G, Wang J and Zeng Y 2020 A modified rabbit model of tracheal stenosis and a household endoscope.
More simplicity and accessibility Acta Cir. Bras. 35 e351104

[34] Behrend M and Klempnauer J 2001 Tracheal reconstruction under tension: an experimental study in sheep Eur. J. Surg. Oncol. EJSO 27 581-8

[35] ten Hallers E J O, Rakhorst G, Marres H A M, Jansen J A, van Kooten T G, Schutte H K, van Loon J-P, van der Houwen E B and Verkerke G J 2004 Animal models for tracheal research Biomaterials 25 1533-43 